\title{
Perigoso mas gostoso: representações sociais do barebacking em Florianópolis
}

\author{
Dangerous but pleasurable: social representations of barebacking in \\ Florianopolis
}

http://dx.doi.org/10.5007/2178-4582.2017v51n1p194

\author{
Andréia Isabel Giacomozzi, Beatriz Pires Coltro e Kelly Vieira Meira \\ Universidade Federal de Santa Catarina, Florianópolis/SC, Brasil \\ Nilceia Antunes \\ Secretaria Municipal de Saúde de Florianópolis/SC, Brasil
}

\begin{abstract}
Realizou-se estudo quantitativo qualitativo e descritivo com 144 pessoas em locais frequentados pela população LGBT, objetivando investigar representações sociais do barebacking, comportamentos de risco, atitudes frente o uso do preservativo e conhecimento sobre HIV/ Aids. Os dados foram analisados com auxílio dos softwares SPSS e SPAD. O grupo apresentou bom conhecimento sobre HIV/Aids, posicionamento favorável ao uso do preservativo e alta porcentagem de participantes já realizaram teste anti-HIV $(65,7 \%)$. O uso consistente do preservativo foi declarado por $45,3 \%$ e $27,2 \%$ declarou que já fez barebacking. O principal motivo para a não utilização do preservativo foi a confiança no parceiro. Surgiram representações do barebacking ligadas ao arrependimento e promiscuidade, porém o prazer foi elemento importante nesta representação.

Palavras-chave: Barebacking, HIV, vulnerabilidade, LGBT.
\end{abstract}

This is a quantitative-qualitative and descriptive study with 144 people in locations frequented by the LGBT community, aiming to investigate social representations of barebacking, risk behaviors, attitudes toward condom use and knowledge about HIV/AIDS. Data were analyzed using SPSS and SPAD. The group had a good knowledge about HIV/AIDS, was in favor of condom use and a high percentage of the participants have already done HIV test (65.7\%). Consistent condom use was declared by $45.3 \%$, and $27.2 \%$ stated that have done barebacking. The main reason for not using condoms was trust in the partner. There were found representations of barebacking linked to repentance and promiscuity, but the pleasure was an important element in this representation.

Keywords: Barebacking, HIV, vulnerability, LGBT.

\section{Introdução}

Estudos vêm alertando (FURNARI, 2003; ANDRADE et al., 2007), a respeito da especial vulnerabilidade dos homens que fazem sexo com homens (HSH) às DST/HIV/Aids. No Brasil, a transmissão sexual do HIV responde por grande parte dos casos de aids. Segundo o banco de dados do Ministério da Saúde, entre 1990 e 1999, a via sexual esteve relacionada a contatos entre homens que fazem sexo com homens em $48 \%$ dos casos ${ }^{1}$. Entre estes, $63,5 \%$ deles declararam-se infectados por exclusivo contato sexual entre homens.

De acordo com a pesquisa PCAP-BR (BRASIL, 2004) realizada sobre atitudes e práticas da população brasileira, a população de gays e outros $\mathrm{HSH}$

1 http://www.aids.gov.br 
de 15 a 49 anos de idade foi estimada em 3,2\%, representando cerca de 1,5 milhões de pessoas. Com essa estimativa de base populacional dos $\mathrm{HSH}$ calculou-se a incidência de aids nesse segmento, que foi estimada em 226,5 por $100.000 \mathrm{HSH}$. Neste mesmo ano, a taxa de incidência para a população geral foi de 19,5 casos por 100.000 habitantes, indicando, portanto, que a taxa de incidência estimada para HSH é 11 vezes maior do que a da população em geral. Além disso, Beloqui (2006) afirma que a possibilidade de gays ou HSH desenvolverem aids é dezoito vezes maior que a dos heterossexuais.

Isso pode estar acontecendo em função do surgimento de práticas de alto risco para a infecção pelo HIV e outras DST entre esta população, como o barebacking. O termo barebacking significa, do inglês, cavalgar ou montar sem cela. De acordo com Léobon e Frigault (2005) este termo era inicialmente empregado em rodeios norte-americanos como uma modalidade de esporte sem proteção, e posteriormente passou a ser utilizado no contexto da comunidade gay norte-americana em meados de 1990 para designar o sexo intencional sem preservativo.

De modo geral, o barebacking tem sido definido como o sexo anal desprotegido entre homens que fazem sexo com homens de forma intencional (ELFORD, 2006; SHERNOFF, 2006). Porém pode haver diferenças quanto ao tipo de vínculo e condição sorológica dos parceiros. Wolitski (2005) utiliza o termo correspondendo ao sexo anal sem preservativo de forma intencional, exceto quando praticado por parceiros primários HIV negativo que mantêm um relacionamento mutuamente monogâmico ou em um relacionamento de proteção negociada.

A partir do exposto, faz-se necessário considerar o surgimento de uma nova forma de ver o risco de maneira positiva (LE BRETON, 2000; SPINK, 2001) que passa a coexistir com a ideia antiga de risco como ameaça e perigo. Silva e Iriart (2010) ressaltam que no barebacking ocorre a valorização da experiência corporal, sensorial, que se concretiza a partir de um contato mais intenso com o outro. Seria um prazer a mais que surge pela expansão e transgressão das fronteiras e limites do próprio corpo. O barebacking pode representar ainda uma estratégia de resistência a um discurso normativo da saúde em relação ao sexo seguro (CROSSLEY, 2002; ROFES, 2002).

Além disso, Dean (2009) afirma que o barebacking não pode ser entendido como sendo restrito à subcultura que o criou, já que ele diz respeito a uma experiência de intimidade sem restrições, seria o desejo de superar a fronteiras entre as pessoas, que está longe de ser exclusiva da comunidade gay. O barebacking iria, portanto, muito além da prática do sexo anal sem preservativo e se inseriria em um conjunto de dispositivos organizados de um grupo. 
Este autor propõe uma distinção entre o barebacking como um comportamento e barebacking como uma identidade. Acrescenta que quando barebacking é abordado a partir de uma perspectiva epidemiológica, a dimensão de fantasia desaparece completamente. Em outras palavras, quando o sexo entre homens é reduzido à problemática da transmissão do vírus HIV, já não é tratado como sexualidade. $\mathrm{O}$ foco esmagador sobre a profilaxia suprimiria as considerações de fantasia, de intimidade e de prazer. Assim, o barebacking seria uma tentativa de recuperar o sexo gay como sexualidade, relegando questões epidemiológicas a um status secundário.

No que tange a relação entre o barebacking e o HIV, Dean (2009) diferencia três categorias de comportamento: o barebacking com o desejo ou intenção de não transmitir o HIV, o barebacking como indiferença ao vírus, e o barebacking como um desejo ou intenção para a transmissão viral. Os praticantes de barebacking poderiam incorrer em qualquer uma dessas três categorias, bem como transitar entre elas, já que estas são categorias de intenção e prática, e não de identidade.

Para melhor compreender tais práticas é importante deslocar o alvo de interesse do âmbito individual para os processos nos quais acontece a construção das identidades, das masculinidades e feminilidades. Para Amâncio (2001), isto é possível no âmbito da teoria das representações sociais de Moscovici. Através desta teoria pode-se situar a totalidade do conceito de gênero, na medida em que ele se refere a processos psicossociológicos onde se cruzam uma dimensão mais psicológica e uma dimensão cultural, podendo-se operar um verdadeiro deslocamento de paradigma e compreender a lógica simbólica do gênero e de que modo as pessoas lhe dão sentido na vida cotidiana.

Para Abric (1998) as representações sociais funcionam como um sistema de interpretação da realidade que rege as relações dos indivíduos com seu meio físico e social, orientando tanto os comportamentos, quanto as relações sociais. Assim, por serem produto e processo das relações entre indivíduos e grupos (MOSCOVICI, 2003) o estudo das representações sociais precisa considerar os contextos simbólicos onde elas circulam.

Moscovici (1988) reconhece a existência de diferentes tipos de representações. Algumas são hegemônicas e compartilhadas por um grande número de indivíduos e grupos sociais, impostas por meio de processos conformistas de influência social (ligadas a sistemas de pensamento mais amplos, como valores ou ideologias), enquanto outras são discutíveis no interior dos grupos sociais e nas relações intergrupais. Dentre estas últimas encontram-se as representações sociais polêmicas, que expressam a busca pela diferenciação grupal ou um conflito intergrupal explícito gerados pela 
polêmica em torno de atributos e valores do grupo; e as representações sociais emancipadas, sustentadas na cooperação intergrupal e compartilhamento de significados, interpretações e símbolos entre os grupos. No caso das representações sociais polêmicas, a representação de um objeto é evocada por oposição a outra representação, acentuando as diferenciações sociais (VALA, 2000). Essas representações se organizam quando a forma de pensar de um grupo sobre um objeto é percebida como uma ameaça para outro grupo; neste caso é a representação sobre o sistema de relações intergrupais que determina a representação sobre um objeto implicado nesta relação.

Além disso, segundo Moscovici (2004) as representações estão intimamente relacionadas com as atitudes, pois essas últimas são uma das dimensões das representações. O conceito de atitudes pretende ser mediador entre a forma de pensar e a forma de agir dos indivíduos, pois tem ligação com os comportamentos. As atitudes permitem identificar o posicionamento de um indivíduo frente à realidade social (VALA, 2000). Assim, estudando as atitudes das pessoas frente ao uso do preservativo, por exemplo, seria possível conhecer previamente seu comportamento com relação ao sexo seguro.

O modelo de crença de saúde utilizado neste estudo é o da Ação Refletida de Fishbein e Ajzen (1975). Essa teoria prevê a intenção comportamental e supõe que o comportamento seja função desta intenção. Uma intenção comportamental é determinada pela atitude do sujeito em relação ao desempenho do comportamento e por normas subjetivas. Portanto, as intenções das pessoas com relação ao uso do preservativo, por exemplo, dependerão das suas atitudes com relação ao uso do preservativo, que por sua vez resultam das suas crenças sobre as consequências do uso ou não uso. A percepção das consequências do uso / não uso do preservativo pode, portanto, afetar a intenção de usá-lo ou não, se os indivíduos acreditarem que as consequências negativas do não uso recaiam sobre si próprios.

Pensando neste contexto da população em questão, este estudo objetivou conhecer melhor as especificidades das pessoas que frequentam lugares específicos LGBT com relação à sua sexualidade, investigando suas representações sociais do barebacking, suas práticas protetivas e de risco, seu conhecimento sobre HIV/Aids e atitudes frente o uso do preservativo.

\section{Método}

\section{Caracterização da pesquisa}

Tratou-se de estudo de natureza descritiva quantitativa e qualitativa. $\mathrm{O}$ estudo foi exploratório, não randômico. Os participantes são frequentadores 
de uma ONG de Florianópolis que trabalha com a população LGBT e de locais específicos desta população, convidados a participar voluntariamente por profissionais da ONG.

\section{Amostra}

Participaram 144 pessoas que frequentam a ONG que trabalha com a população LGBT e outros locais de acesso desta população, como bares, boates, etc. A média de idade dos participantes foi de 25 anos e 5 meses, com desvio padrão de 7,33. Com relação à procedência dos participantes, 47,2\% declararam ser de Florianópolis, $12,5 \%$ do interior de SC, 38,9\% de outros estados brasileiros e 1,4\% não respondeu a esta questão. No que tange a orientação sexual dos participantes, 55,2\% declarou ser Homossexual, 23,1\% Bissexual e 21,7\% Heterossexual. Dentre os que se declararam Homossexual, $14,3 \%$ declarou-se HSH, 69,2\% Gay e 16,5\% Lésbica. Decidiu-se por manter na análise os questionários daqueles que se declararam heterossexual, pois foi verificado que muitos deles afirmaram ser HSH mesmo tendo marcado a categoria Heterossexual.

Com relação à escolaridade dos participantes, a maior proporção $34,3 \%$ declarou ter ensino médio completo, $21 \%$ ensino superior incompleto, $16,1 \%$ ensino médio incompleto, $8,4 \%$ ensino superior completo e igual percentual $(8,4 \%)$ para ensino fundamental incompleto; $7 \%$ declarou ter ensino fundamental completo e $4,9 \%$ declarou não ter estudado.

\section{Instrumento}

Foi utilizada a entrevista diretiva aplicada individualmente. As questões podem ser classificadas em quatro grupos: O primeiro se refere às características individuais dos participantes, tais como: identidade de gênero, idade e nível de escolaridade. O segundo grupo de questões diz respeito ao uso de álcool e outras drogas, vivência de violência e preconceito. O terceiro grupo envolve questões sobre comportamento e práticas sexuais, uso do preservativo, além dos motivos do não uso (conforme o caso) e a prática do barebacking e evocações sobre a mesma. O quarto grupo foi formado por uma escala de atitudes frente o uso do preservativo ${ }^{2}$ e um teste de conhecimento ligado ao HIV/Aids ${ }^{3}$ e autopercepção do conhecimento sobre esta epidemia.

\footnotetext{
2 Escala do tipo Likert com cinco pontos, composta de 12 itens. A consistência entre os itens, em estudo anterior (CAMARGO; BOTELHO; SOUZA, 2001), foi moderada $(\alpha=0,75)$.

3 Consiste no sub-teste "O vírus da aids e sua transmissão", integrante de uma medida sobre conhecimento da aids construída por Camargo, Barbará e Bertoldo (2005).
} 
Os participantes foram contatados na sede da ONG, bem como em outros locais de frequência específica desta população pelos agentes da ONG, comunicados sobre a pesquisa e seus objetivos e convidados a participar. Após darem seu consentimento, por meio da assinatura do termo de consentimento livre e esclarecido, o pesquisador os convidava a responder as questões. As entrevistas aconteceram de forma individual.

\section{Análise de dados}

As respostas fechadas foram colocadas em um banco de dados do software SPSS (pacote estatístico para as ciências sociais). Foram realizadas análises estatísticas descritivas e de correlação entre as variáveis. As respostas à questão de evocação livre sobre barebacking foram digitadas em um banco de dados e analisadas com auxílio do software SPAD-T Systhème Portable pour 1'Analyse des Données Textuelles - SPAD-T (LEBART; SALEM, 1988). Com este software é possível explorar o campo das representações sociais através da análise de correspondência, pois ele executa uma análise textual que permite aplicar uma ampla variedade de procedimentos estatísticos, tais como diferentes versões da análise de correspondência e análise de agrupamento.

Para o estudo das representações sociais, os fatores da AFC podem ser interpretados como princípios organizadores que explicitam as similaridades e diferenças da representação social em diferentes grupos. Pode ser uma supra-estrutura, ideal para verificar variações no campo representacional de indivíduos com características diferentes (DOISE; CLEMENCE; LORENZICIOLDI, 1992).

\section{Resultados}

\section{Relações amorosas e sexuais}

Quanto aos relacionamentos, a maior proporção $(67,6 \%)$ declarou não ter parceiro fixo, enquanto $32,4 \%$ dos participantes declararam ter. Além disso, $62,7 \%$ declarou ter tido relações sexuais com mais de uma pessoa nos últimos 12 meses, enquanto $26,8 \%$ disse ter tido com somente uma pessoa e $10,6 \%$ não teve relações sexuais neste período.

O uso do preservativo em todas as relações sexuais nos últimos 12 meses foi declarado por $45,3 \%$, enquanto $40,9 \%$ afirmou ter utilizado somente em algumas relações, $10,9 \%$ afirmou não ter utilizado e 2,9\% disseram não saber 
se utilizaram. Além disso, ao final do questionário havia a seguinte questão: "Se você é profissional do sexo, já fez sexo sem preservativo a pedido do cliente?", para a qual 13,9\% afirmaram que sim. Para os que afirmaram não ter utilizado o preservativo nos últimos 12 meses, perguntaram-se os motivos da não utilização. As respostas dos participantes foram agrupadas em categorias conforme demonstra a Figura 1.

Observou-se que o principal motivo, citado por $41,9 \%$ dos participantes, para a não utilização do preservativo foi o de confiar no parceiro. Além disso, $12,9 \%$ afirmou que não utilizou para sentir mais prazer, e igual proporção porque estava sob efeito de álcool e/ou outras drogas. Em quarto lugar, com $8,1 \%$ das respostas foi citado o "tesão". O fato de não ter o insumo no momento e o de que o parceiro não quis utilizar foi referido por $2,8 \%$ e $1,4 \%$ referiu que foi por irresponsabilidade, a pedido do cliente em uma relação comercial e por esquecimento.

Figura 1. Motivos para o não uso do preservativo nos últimos 12 meses

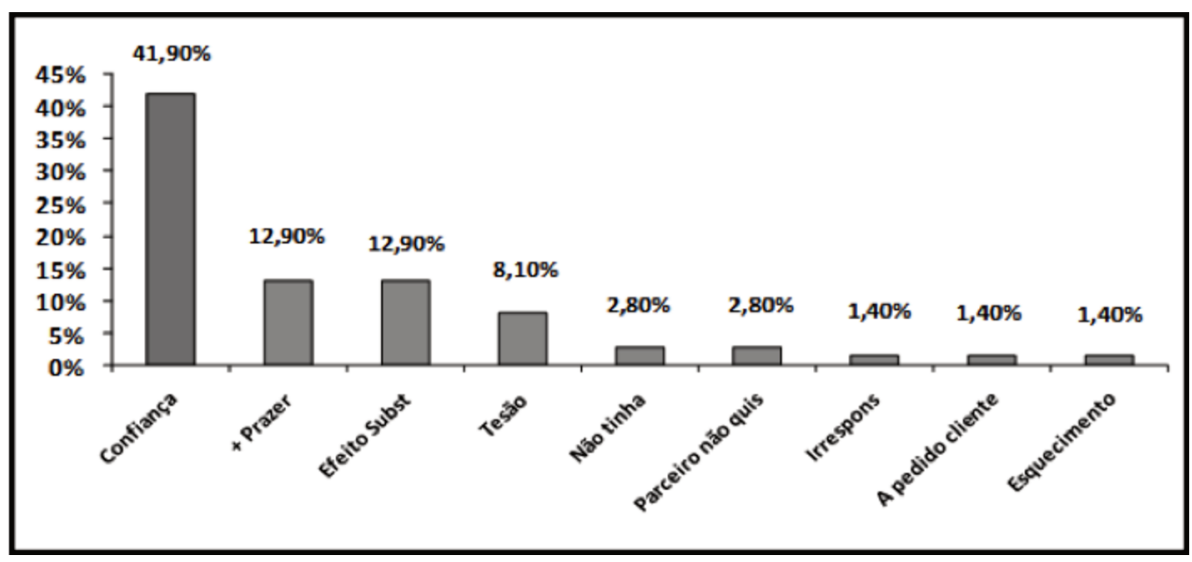

Fonte: Dados da pesquisa

\section{Práticas de risco e violência}

Foi perguntado aos participantes se eles utilizam álcool e outras drogas e se já mantiveram relações sexuais sob efeito destas substâncias. O uso do álcool foi declarado por $91,9 \%$ dos participantes, enquanto $46,5 \%$ declarou já ter utilizado maconha, 20,1\% cocaína, 4,2\% crack. Além disso, observou-se que $66,7 \%$ dos participantes afirmaram que já tiveram relações sexuais sob efeito de álcool e/ou outras drogas. Com relação à prática do barebacking, 46,9\% afirmou que já ouviu falar e $27,2 \%$ declarou que já participou desta prática. 
Quando questionados sobre agressões sofridas, a maior proporção $(82,4 \%)$ afirmou que nunca foi agredido, enquanto $17,6 \%$ relataram já ter sofrido agressão; além disso, $48,2 \%$ afirmaram já ter sofrido algum tipo de preconceito e $15,4 \%$ declarou que já participou de brigas.

\section{Conhecimento sobre DST e HIV/Aids}

A grande maioria dos participantes $(96,5 \%)$ declarou saber o que é uma Doença Sexualmente Transmissível (DST). A maioria (82,3\%) afirmou nunca ter tido uma DST, enquanto $16,3 \%$ afirmou já ter tido e 1,4\% disse não saber se teve. Além disso, $62,5 \%$ declarou considerar-se bem informado sobre aids, enquanto $15,3 \%$ disse não ser e $18,8 \%$ não sabe.

Para verificar o conhecimento do grupo sobre aids, foi aplicado um subteste de conhecimento sobre a transmissão do vírus HIV (dimensão vírus e transmissão da aids) de Camargo, Barbará e Bertoldo (2005). A média de conhecimento do grupo foi de 7,33 (desvio padrão=1,79) dentre 10 possíveis. Tal média de acerto se encontra acima da nota de corte de 7 acertos do subteste vírus da aids e transmissão da doença, parte integrante da medida sobre conhecimento acerca de aids, o que indica alto índice de conhecimento deste grupo frente a doença.

\section{Atitudes frente o uso do preservativo e testagem de HIV}

Com relação à atitude frente o uso de preservativo, foi observado que os participantes obtiveram média de 3,61, numa escala de 1 - atitude desfavorável a 5 - atitude favorável - (desvio padrão 0,63 ). Por ser acima do ponto médio da escala, 3 , percebe-se que o grupo posicionou-se favoravelmente ao uso do preservativo.

Com relação ao teste de HIV, observou-se que $65,7 \%$ dos entrevistados já realizaram teste, e a aceitabilidade do mesmo é bastante boa, pois $75 \%$ disseram que gostariam de fazer o teste para o HIV.

As variáveis Conhecimento sobre a aids e Atitude diante do uso do preservativo correlacionaram-se, mas com índice de pequena magnitude ( $\mathrm{r}=0$, $19 ; \mathrm{p}<0,05)$. Portanto, quanto maior o conhecimento sobre HIV/Aids, mais favoráveis as atitudes frente o uso do preservativo entre os participantes.

\section{Representações sociais do barebacking}

Solicitou-se aos participantes que já ouviram falar de barebacking que citassem as três primeiras palavras que lhes viessem à cabeça com relação ao termo. As respostas foram digitadas em um banco de dados e analisadas com 
auxílio do software SPAD-T. Com a Análise Fatorial de Correspondência AFC, obtiveram-se 3 fatores. O Fator 1 explica 21,40\% da inércia, o segundo fator explica $16,71 \%$ e o terceiro fator explica $15,59 \%$, totalizando $53,70 \%$ da variância total das respostas. Utilizou-se das variáveis Nível de estudo e Uso de preservativo para associação com os elementos.

O primeiro fator traz elementos que associam a prática do barebacking à promiscuidade e ao arrependimento, bem como a consciência de não praticar este tipo de relação sexual. O primeiro pólo ligado a este fator, ao qual se associaram as variáveis Não sabe se usou preservativo e Nível superior completo, apresenta o arrependimento, a ansiedade e a promiscuidade relacionados ao barebacking. Em contraposição, o segundo pólo, ainda ligado ao primeiro fator, ao qual se associaram as variáveis Não usou preservativo e Nível fundamental incompleto traz a preocupação em não realizar esta prática e do cuidar. A Tabela 1 apresenta as palavras associadas ao Fator 1.

Tabela 1 - Análise de correspondências do Fator 1

\begin{tabular}{l|l|l|l|l|l|l|l}
\hline Modalidades & Coord. & $\begin{array}{l}\text { Contr. } \\
\text { Absoluta }\end{array}$ & Cos $^{2}$ & Modalidades & Coord. & $\begin{array}{l}\text { Contr. } \\
\text { Absoluta }\end{array}$ & Cos $^{2}$ \\
\hline $\begin{array}{l}\text { Não sabe se usou } \\
\text { preservativo }\end{array}$ & -1.61 & 44.5 & 0,61 & $\begin{array}{l}\text { Não usou } \\
\text { preservativo }\end{array}$ & 0.81 & 18.7 & 0.36 \\
\hline Superior Completo & -0.62 & 9.3 & 0.16 & $\begin{array}{l}\text { Fundamental } \\
\text { Incompleto }\end{array}$ & 0.60 & 8.1 & 0.29 \\
\hline Elementos & Coord. & Contr. & Cos $^{2}$ & Elementos & Coord. & Contr. & Cos $^{2}$ \\
\hline Arrependimento & -1.77 & 35.8 & 0.60 & Não praticar & 0.33 & 8.6 & 0.33 \\
\hline Ansiedade & -1.20 & 16.4 & 0.65 & Cuidar & 0.78 & 7.0 & 0.37 \\
\hline Promiscuidade & -0.62 & 4.3 & 0.10 & & & & \\
\hline
\end{tabular}

O segundo fator traz novamente a questão do arrependimento como indício de que tal prática tem sido realizada pelos participantes da pesquisa, citando a consciência do perigo associado, porém revela o prazer sentido através da palavra gostoso. O primeiro pólo ligado a este fator, ao qual se associaram as variáveis Não sabe se usou preservativo, Não usou Preservativo e Nível fundamental incompleto, apresenta os elementos arrependimento, cuidar e perigo. O segundo pólo, em oposição ao primeiro, ao qual se associaram as variáveis Usou preservativo algumas vezes, e Nível superior completo apresenta gostoso como palavra de maior contribuição, marcando o prazer como uma associação importante ao barebacking. Além disso, traz outros elementos como irresponsabilidade, promiscuidade e o descuido relacionado à prática. A Tabela 2 apresenta as palavras associadas ao fator. 
Tabela 2 - Análise de correspondências do Fator 2

\begin{tabular}{l|l|l|l|l|l|l|l}
\hline Modalidades & Coord. & $\begin{array}{l}\text { Contr. } \\
\text { Absoluta }\end{array}$ & Cos $^{2}$ & Modalidades & Coord. & $\begin{array}{l}\text { Contr. } \\
\text { Absoluta }\end{array}$ & Cos $^{2}$ \\
\hline $\begin{array}{l}\text { Não sabe se usou } \\
\text { preservativo }\end{array}$ & -1.19 & 31.0 & 0.33 & $\begin{array}{l}\text { Usou algumas } \\
\text { vezes }\end{array}$ & 0.22 & 8.3 & 0.27 \\
\hline $\begin{array}{l}\text { Não usou } \\
\text { preservativo }\end{array}$ & -0.92 & 30.9 & 0.46 & $\begin{array}{l}\text { Superior } \\
\text { Completo }\end{array}$ & 0.42 & 5.6 & 0.07 \\
\hline $\begin{array}{l}\text { Fundamental } \\
\text { Incompleto }\end{array}$ & -0.57 & 9.6 & 0.27 & & & & \\
\hline Elementos & Coord. & Contr. & Cos $^{2}$ & Elementos & Coord. & Contr. & Cos $^{2}$ \\
\hline Arrependimento & -1.32 & 25.6 & 0.33 & Gostoso & 0.43 & 5.4 & 0.17 \\
\hline Cuidar & -0.66 & 6.5 & 0.27 & $\begin{array}{l}\text { Irresponsa- } \\
\text { bilidade }\end{array}$ & 0.14 & 4.8 & 0.29 \\
\hline Perigo & -0.15 & 4.0 & 0.22 & Promiscuidade & 0.56 & 4.6 & 0.09 \\
\hline
\end{tabular}

O terceiro fator apresenta o juízo de que o barebacking é uma promiscuidade, relaciona-o com morte e ansiedade e traz novamente o prazer imbricado na prática. O primeiro pólo ligado a este fator, ao qual se associaram as variáveis Nível médio incompleto e Usou preservativo algumas vezes apresenta a palavra gostoso referindo novamente o prazer sentido com a prática do barebacking. $\mathrm{O}$ segundo pólo ligado a este fator traz os elementos de promiscuidade, morte, preocupação em não praticar o barebacking e a ansiedade relacionada à prática. A Tabela 3 apresenta as palavras associadas ao fator 3 .

Tabela 3 - Análise de correspondências do Fator 3

\begin{tabular}{l|l|l|l|l|l|l|l}
\hline Modalidades & Coord. & $\begin{array}{l}\text { Contr. } \\
\text { Absoluta }\end{array}$ & $\operatorname{Cos}^{2}$ & Modalidades & Coord. & $\begin{array}{l}\text { Contr. } \\
\text { Absoluta }\end{array}$ & Cos $^{2}$ \\
\hline $\begin{array}{l}\text { Médio } \\
\text { Incompleto }\end{array}$ & -0.44 & 15.9 & 0.39 & $\begin{array}{l}\text { Superior } \\
\text { Completo }\end{array}$ & 1.21 & 49.2 & 0.60 \\
\hline $\begin{array}{l}\text { Usou algumas } \\
\text { vezes }\end{array}$ & -0.26 & 12.2 & 0.37 & $\begin{array}{l}\text { Usou todas } \\
\text { as vezes }\end{array}$ & 0.43 & 9.2 & 0.18 \\
\hline Elementos & Coord. & Contr. & $\operatorname{Cos}^{2}$ & Elementos & Coord. & Contr. & Cos $^{2}$ \\
\hline Gostoso & -0.26 & 17.0 & 0.48 & Promiscuidade & 1.62 & 41.1 & 0.71 \\
\hline & & & & Morte & 0.65 & 6.6 & 0.42 \\
\hline & & & & Não praticar & 0.23 & 6.0 & 0.17 \\
\hline
\end{tabular}




\section{Discussão dos resultados}

O objetivo deste estudo foi investigar o uso do preservativo, motivos do não uso, realização de teste de detecção do HIV, conhecimentos e atitudes frente o uso do preservativo, bem como a representação social do barebacking de pessoas que frequentam locais de acesso da população LGBT de Florianópolis.

Com relação ao uso do preservativo, observou-se que o uso em todas as relações sexuais nos últimos 12 meses foi declarado por $45,3 \%$, porém $40,9 \%$ afirmou ter utilizado somente em algumas relações. Estes percentuais são mais baixos do que os observados no estudo PCAP-BR (BRASIL, 2004) do Ministério da Saúde, cujos dados apontam que 59,8\% dos HSH entrevistados reportaram uso de preservativo na última relação sexual.

Além disso, é importante ressaltar que 13,9\% dos participantes afirmaram que já fizeram sexo sem preservativo em sua prática profissional, a pedido do cliente. Em estudo de Nardi (2006), realizado com garotos de programa e clientes na região metropolitana de Porto Alegre, afirma-se que foi encontrado um desacordo entre o relato dos donos/gerentes das casas de prostituição e o relato dos garotos frente ao uso sistemático do preservativo. Enquanto a grande maioria dos garotos $(94,3 \%)$ afirma que usa sempre preservativo, os gerentes/donos citam que esse uso é bem menor, tendo em vista a pequena quantidade de preservativos encontrada na limpeza dos darkrooms e dos quartos disponibilizados pelas casas.

Para os que responderam não ter utilizado o preservativo nos últimos 12 meses, formulou-se uma questão aberta sobre os motivos da não utilização. A confiança foi o principal motivo, citada em $41,9 \%$ das respostas. Estudos anteriores com mulheres casadas (GIACOMOZZI; CAMARGO, 2004), profissionais do sexo (OLTRAMARI; CAMARGO, 2004), estudantes do ensino médio do ensino noturno de periferias brasileiras (CAMARGO et al., 2010), estudantes brasileiros e franceses (GIACOMOZZI; CAMARGO, 2011) e usuários de álcool e outras drogas em atendimento em CAPS-ad (GIACOMOZZI, 2011) também observam que a confiança é um dos principais motivos citados para a não utilização do preservativo nas relações sexuais.

Outro motivo citado para a não utilização do preservativo inclui o fato de querer sentir mais prazer. Isto também foi encontrado em pesquisas anteriores sobre barebacking, onde se verificou uma preocupação excessiva por acumular ou intensificar as sensações (SILVA, 2009; SILVA; IRIART, 2010).

O uso de álcool e outras drogas pelos participantes pode ser considerado um indicativo de vulnerabilidade frente às DST/HIV/Aids, uma vez que o fato de não ter utilizado preservativo por estar sob efeito de álcool e ou outras drogas 
foi o terceiro motivo mais citado neste estudo. Além disso, é importante notar que $91,9 \%$ dos participantes afirmaram utilizar álcool, 46,5\% maconha, 20,1\% cocaína e 4,2\% crack. Estas porcentagens são bem superiores às encontradas em estudo do "II Levantamento Domiciliar sobre Uso de Drogas no Brasil", realizado pelo CEBRID, em 2005 (CARLINI et al., 2007), que mostra que na região sul o "uso na vida" das drogas (que não álcool e tabaco) foi de 14,8\%. Já o "uso na vida" do álcool foi de $73,9 \%$, o consumo de maconha ficou em $9,7 \%$, de cocaína $(3,1 \%)$ e de crack $(1,1 \%)$.

No que concerne a relação com comportamentos sexuais arriscados, vários estudos (COOK et al., 2002; SCIVOLETTO et al., 1999; TAPERT et al, 2001; TAQUETTE et al., 2005) observaram uma associação entre o uso de bebidas alcoólicas e ou outras drogas e ter DST.

A vivência do preconceito entre os participantes parece ser uma constante, uma vez que quase metade $(48,2 \%)$ afirmou já ter sofrido algum tipo de preconceito e 17,6\% relataram já ter sofrido agressão. Estudos demonstram que a manifestação explícita do preconceito tem diminuído nas últimas décadas, mas somente contra grupos sociais protegidos pela norma do antipreconceito (PETTIGREW; MEERTENS, 1995; SEARS; HENRY, 2003). Assim, o preconceito contra homossexuais ainda persiste (LACERDA; PEREIRA; CAMINO, 2002; MELTON, 1989).

Boa parte dos participantes $(62,5 \%)$ consideram-se bem informados sobre aids. E isto parece fazer sentido em função de que o grupo obteve média 7,33 no sub-teste de conhecimento sobre aids, indicando alto conhecimento sobre transmissão do vírus. No que tange às atitudes frente o uso do preservativo, os participantes do estudo apresentaram atitudes favoráveis a utilização, uma vez que obtiveram média de 3,61.

Com relação ao modelo de crença de saúde utilizado neste estudo, observouse que as variáveis Conhecimento sobre a aids e Atitude diante do uso do preservativo correlacionaram-se, portanto quanto maior o conhecimento sobre HIV/Aids, mais favoráveis as atitudes frente o uso do preservativo entre o grupo. Sabe-se que o fator conhecimento é bastante importante para adoção de condutas protetoras, um baixo escore neste tipo de teste associado a outros determinantes pode ser um fator de risco e vulnerabilidade do indivíduo. As atitudes favoráveis ao uso do preservativo, porém, não se correlacionaram com a utilização do mesmo, tampouco o conhecimento sobre a transmissão do HIV.

No que tange a testagem para o HIV observou-se dentre os participantes deste estudo uma porcentagem elevada $(65,7 \%)$, quando comparado com estudos anteriores. Em estudo com estudantes do ensino médio do turno noturno de Florianópolis, Itajaí e Balneário Camboriú, Camargo et al. (2010) 
observaram que a maioria dos participantes $(80,1 \%)$ disse nunca ter realizado o teste para detecção do vírus. Estes dados são corroborados pelos dados encontrados no estudo PCAP-BR de 2004 que mostrou uma maior proporção de HSH testados (33\%), quando comparados aos homens que fazem sexo exclusivamente com mulheres $(21 \%)$.

De acordo com dados do Ministério da Saúde (BRASIL, 2010), em quatro anos (2005 à 2009), o número de testes de HIV distribuídos e pagos pelo SUS mais que dobrou: passou de 3,3 milhões para 8,9 milhões de unidades. $\mathrm{O}$ resultado pode ser percebido no aumento da testagem para o HIV no país, que foi ampliada de 23,9\% em 1998 para 38,4\% em 2008. Contudo, a realização do diagnóstico precoce é um grande desafio, pois se estima que 630 mil pessoas vivam com o vírus no país. Destas, pelo menos, 255 mil não sabem disso ou nunca fizeram o teste de HIV.

Com relação às Representações Sociais dos participantes sobre o barebacking, a partir da análise fatorial de correspondência, obtiveram-se três fatores. O primeiro fator traz elementos que associam a prática do barebacking à promiscuidade, e ao arrependimento, bem como o desejo de não praticar este tipo de prática. Observou-se que as pessoas que afirmaram não saber se utilizaram preservativo nos últimos 12 meses e com nível superior completo evocaram o arrependimento, a ansiedade e a promiscuidade relacionados ao barebacking. O segundo fator traz novamente a questão do arrependimento, citando a consciência do perigo associado, porém revela o prazer sentido através da palavra gostoso. O terceiro fator apresenta o juízo de que o barebacking é uma promiscuidade, relaciona-o com morte e ansiedade e traz novamente o prazer imbricado na prática.

O elemento arrependimento apresenta indícios de que os participantes já experimentaram esta prática, além de o prazer ter se associado muito fortemente às evocações dos participantes, indicando que se deve abordar esta temática nos trabalhos de prevenção e promoção da saúde junto a esta população, bem como a divulgação dos serviços que realizam o teste HIV e facilitação do acesso ao preservativo.

Sendo assim, pode-se observar que as representações encontradas dentre este grupo não foram homogêneas e sim, polêmicas. Wagner(1998) observa que a característica holomórfica das representações está presente principalmente na classe de representações sociais polêmicas, onde divisões de grupo e ideologias cotidianas associadas são mais salientes do que o conhecimento do senso comum em geral. Este autor sustenta que as representações sociais polêmicas originam-se no curso de conflitos sociais, pois elas caracterizam subdivisões na sociedade, são mutualmente exclusivas e determinam relações antagônicas entre os grupos. 
Pode-se perceber ainda, que existe entre os participantes, normas sociais que indicam uma direção da prática do sexo seguro, embora o prazer do barebacking seja reconhecido e já tenha sido experimentado por parte deles. As normas desempenham uma função de destaque nos pertencimentos e nas relações intergrupais, pois elas são importantes na regulação dos pensamentos, sentimentos e comportamentos dos membros do grupo (RODRIGUES et al., 2012), portanto se constituem como âncoras de representações sociais polêmicas, modelando seus conteúdos semânticos, regulando seus elementos atitudinais e as práticas que mapeiam os contornos dos grupos (HOGG, 2010). Tal autor sustenta que, como os grupos estão envolvidos na construção de quem as pessoas são, as normas grupais exercem uma função prescritiva, dizendo para os indivíduos as práticas que eles devem realizar enquanto membros do grupo no qual eles se sentem pertencentes.

Desta forma, as normas, de uma forma geral, são definidas como processos sociais de caráter descritivo e prescritivo, ou seja, além de se referirem ao que é feito em um determinado contexto também ditam como os membros de um determinado grupo devem se comportar para receberem aprovação ou evitar sanções por parte dos outros membros, o que as caracterizam como imperativos morais (TORRES; RODRIGUES, 2011). Assim, entende-se que como a presente pesquisa foi realizada por ONG conhecida por trabalhos de prevenção de DST/HIV/Aids entre a população LGBT, as respostas dos participantes tenderam a apresentar as normas sociais de prevenção como legitimando as práticas deste grupo, sem deixar de reconhecer no entanto, que a prática do barebacking está também presente neste contexto.

De acordo com Silva e Iriart (2010) o barebacking encontra-se conectado a um discurso contemporâneo que faz referência à liberdade de escolha individual, como também à necessidade de viver intensamente o momento presente, quando o amanhã se torna muito imprevisível ou incerto. Por outro lado, também se produz uma sensação de maior intimidade ou ligação entre os parceiros. Esta liberdade sensual e sensorial desafiaria os limites ou fronteiras do próprio corpo, estabelecendo um novo sentido, uma marca ou referência para a própria vida.

Assim, de acordo com Dean (2009) percebe-se que o barebacking tem dado origem a uma subcultura distinta, definida não somente pela sua distância com a sociedade heteronormativa, mas também da própria sociedade gay. Derivada da sociologia do desvio, a teoria das subculturas formula um modelo para descrever comunidades urbanas dominadas por pessoas cujos códigos de comportamento partem da contraposição às normas 
sociais. Assim, a visualização de tais grupos como subculturas permitiria "despatologizar" suas diferenças. Alguns "barebackers" americanos têm associado suas práticas o tipo de vida perseguido por skatistas por exemplo, vendo na subcultura do skate uma ética de risco organizado que ajudaria a racionalizar o sexo arriscado.

\section{Considerações finais}

Os resultados desta pesquisa mostraram que os participantes apresentaram atitudes favoráveis com relação à utilização do preservativo e alto conhecimento sobre transmissão e de testagem do HIV, porém o preservativo não foi sistematicamente utilizado nos últimos 12 meses e a prática do barebacking parece ser comum entre o grupo.

As representações sociais do barebacking trazem elementos de preocupação em não praticar e cuidar, porém também apresentam o prazer como elemento central associado. É necessário, portanto que a dimensão do prazer seja considerada, tanto em trabalhos preventivos, quanto em trabalhos onde a redução de danos seja a temática principal, para que se possa dialogar a partir da verdade dos sujeitos e grupos a respeito.

Outro aspecto importante a ser trabalhado é o estabelecimento de políticas de prevenção, assistência e direitos humanos para a população LGBT, como o fortalecimento da oferta de testes anti-HIV, bem como a luta contra o preconceito e a homofobia vivenciados pelos participantes, fato que os afasta das instituições de saúde, educação, dentre outras.

É necessário levar em consideração as questões culturais em que as pessoas estão inseridas e que colaboram para a melhor aceitação ao uso ou não do preservativo. É fato que a clareza da importância sobre o uso do preservativo não sugere que a prática de seu uso ocorra, pois se percebeu nessa pesquisa uma distância entre o avançado nível de conhecimento em relação à transmissão do HIV/Aids e comportamentos que envolvam o sexo seguro.

Além disso, é necessário o fomento à pesquisa e ao conhecimento sobre aids, preconceito, equidade e homofobia, para que se possa avançar na compreensão das interações destas variáveis psicossociais e suas relações com a vulnerabilização ao HIV/Aids dessa população, bem como o investimento em campanhas televisivas que explorem o lúdico e o prazer das relações e com isso ampliar o significado da camisinha para além da prevenção de doenças e ou da morte como feito no passado. 


\section{Referências}

ABRIC, J. C. A abordagem estrutural das representações sociais. In: MOREIRA, A. S. P.; OLIVEIRA, D. C. (Orgs.). Estudos interdisciplinares de representação social. Goiânia: AB, 1998. p. 27-38.

AMÂNCIO, L. O Gênero na Psicologia: uma história de desencontros e rupturas. Psicologia, Lisboa, v. 15, n. 1, p. 9-26, 2001.

ANDRADE, S. M. O. el al. Vulnerabilidade de homens que fazem sexo com homens, no contexto da aids. Cadernos de Saúde Pública, Rio de Janeiro, v. 23, n. 2, p. 479-482, fev. 2007.

BELOQUI, J. Risco relativo para Aids dos homossexuais masculinos no Brasil. Cadernos pela Vida, São Paulo, n. 42, p. 16-19, jun. 2006.

BRASIL. Ministério da Saúde. PCAP. Secretaria de Vigilância em Saúde. Programa Nacional de DST e Aids. Pesquisa de Conhecimento, Atitudes e Práticas na População Brasileira de 15 a 54 anos. Secretaria de Vigilância em Saúde, Programa Nacional de DST e Aids. 2004.

BRASIL. Ministério da Saúde. Boletim Epidemiológico (versão preliminar). 2010. Disponível em: <http://www.aids.gov.br/pagina/boletim-epidemiologico> . Acesso em: 20 out. 2006.

CAMARGO, B. V.; BARBARÁ, A.; BETOLDO, R. Um instrumento de medida da dimensão informativa da representação social da aids. In: IV Jornada Internacional e II Conferência Brasileira sobre Representações Sociais: Teoria e Abordagens Metodológicas, João Pessoa, 4, 2005, p. 1385-1395.

CAMARGO, B. V.; BOTELHO, L. J.; SOUZA, E. S. B. AIDS, sexualidade e atitudes sobre a proteção contra o HIV: um estudo descritivo com adolescentes do nível médio da rede de ensino (Florianópolis, Itajaí e Balneário Camboriú). Relatório Técnico de Pesquisa. Florianópolis: UFSC/LACCOS, 2001. p. 1- 42.

CAMARGO, B. V. et al. Relações amorosas, comportamento sexual e vulnerabilidade de adolescentes afrodescendentes e brancos em relação ao HIV/Aids. Saúde e Sociedade (USP), São Paulo, v. 19, supl. 2, p. 36-50, dez. 2010.

CARLINI, E. A. et al. II Levantamento domiciliar sobre o uso de drogas psicotrópicas no Brasil: estudo envolvendo as 108 maiores cidades do país - 2005. Brasília, DF: Secretaria Nacional Antidrogas. 2007.

COOK, R. L.; POLLOCK, N. K.; RAO, A. K.; CLARK, D. B. Increased prevalence of herpes simplex virus type 2 among adolescent women with alcohol use disorders. Journal on Adolescent Health, v. 30, p. 169-174, 2002.

CROSSLEY, M. L. The perils of health promotion and the 'barebacking' backlash. Health, London, v. 6, n. 1, p. 47-68, 2002.

DEAN, T. Unlimited intimancy: Reflections on the Subculture of Barebacking. The University of Chicago Press: Chicago, 2009. 256 p.

DOISE, W.; CLÉMENCE, A.; LORENZI-CIOLDI, F. Répresentations sociales et analyses de données. Presses Universitaires de Grenoble: Grenoble. 1992. 264 p. 
ELFORD, J. Changing patterns of sexual behaviour in the era of highly active antiretroviral therapy. Curr Opin Infect Disease, v. 19 n. 1, p. 26-32, 2006.

FISHBEIN, M.; AJZEN, I. Belief, attitude, intention and behavior: An introduction to theory and research. Addison-Wesley Pub: Reading. 1975. 480 p.

FURNARI, S. L. Sexo oral e HIV entre homens que fazem sexo com homens. Cadernos de Saúde Pública, Rio de Janeiro, v. 19, n. 6, p. 1841-1844, nov./dez. 2003.

GIACOMOZZI, A. I. Representações sociais da droga e vulnerabilidade de usuários de CAPS ad em relação às DST/HIV/Aids. Estudos e Pesquisas em Psicologia (UERJ), Rio de Janeiro, v. 11, n. 3, p. 776-795, 2011.

GIACOMOZZI, A. I.; CAMARGO, B. V. Eu confio no meu marido: estudo da representação social de mulheres com parceiro fixo sobre a prevenção da AIDS. Psicologia Teoria e Prática, v. 6 , n. 1, p. 31-44, 2004.

GIACOMOZZI, A. I.; CAMARGO, B. V. Vulnerabilidade de adolescentes afrodescendentes e caucasianos em relação ao HIV/SIDA. Psicologia, Saúde \& Doenças, Lisboa, v. 12, n. 1, p. 143-160, 2011.

HOGG, M. A. Influence and Leadership. In: FISKE S. T., GILBERT D. T., LINDZEY, G. (Eds.). The handbook of social psychology. New York: Wiley, 2010. p. 1166-1207.

LACERDA, M.; PEREIRA, C.; CAMINO, L. Um estudo sobre as formas de preconceito contra homossexuais na perspectiva das representações sociais. Psicologia: Reflexão e Crítica, Porto Alegre, v. 15, n. 1, p. 165-178, 2002.

LEBART, L.; SALEN, A. Analyse statistique des donnés textuelles. Paris: Dunod. 1988, 216 p.

LE BRETON, D. Passions du risque. Paris: Éditions Métailié. 2000. 189 p.

LÉOBON, A.; FRIGAULT, L-R. La sexualité bareback: d'une culture de sexe à la réalité des prises de risque. 2005. Disponível em: <http://www.gaystudies.org/article_leobon_bareback. pdf $>$. Acesso em: 20 out. 2006.

MELTON, G. B. Public policy and private prejudice: Psichology and law on gay rigths. American Psychologist, v. 44, n. 6, p. 933-940, 1989.

MOSCOVICI, S. Notes towards a description of social representations. European Jornal of Social Psychology, v. 18, n. 3, p. 211-250, jul. 1988.

MOSCOVICI, S. O fenômeno das representações sociais. In: MOSCOVICI, S. (Org.). Representações sociais: investigações em psicologia social. Petrópolis: Vozes, 2003. p. 29109.

MOSCOVICI, S. Representações sociais: investigação em psicologia social. Tradução Pedro A. Guareschi. Petrópolis: Vozes. 2004. 404 p.

NARDI, H. C. Poder, sexo e o preço do prazer: processos de subjetivação e prostituição masculina. In: ALMEIDA, C.; GOLIN, C.; POCAHY, F. (Orgs.). Prazer também tem preço: saúde, prostituição e cidadania. Porto Alegre: Nuances. 2006. p. 47-71. 
OLTRAMARI, L. C.; CAMARGO, B. V. Representação social de mulheres profissionais do sexo sobre a AIDS. Estudos de Psicologia, Natal, v. 9, n. 2, p. 317-324, mai/ago. 2004.

RODRIGUES, A.; ASSMAR, E. M. L.; JABLONSKI, B. Psicologia Social. Petrópolis: Vozes. 2012.

ROFES, E. Desires as defiance: gay male sexual subjectivities and resistance to sexual health promotion. Health Education Journal, v. 61, n. 2, p. 125-137, 2002.

SCIVOLETTO, S. et al. Relação entre consumo de drogas e comportamento sexual de estudantes de segundo grau de São Paulo. Revista Brasileira de Psiquiatria, São Paulo, v. 21, n. 2, p. 87-94, 1999.

SILVA, L. A. V. Barebacking e a possibilidade de soroconversão. Cadernos de Saúde Pública, Rio de Janeiro, v. 25, n. 6, p. 1381-1389, 2009.

SILVA, L. A. V., IRIART, J. A. B. Práticas e sentidos do barebacking entre homens que vivem com HIV e fazem sexo com homens. Interface, Botucatu, v. 14, n. 35, p. 739-752, dez. 2010.

SHERNOFF, M. Condomless sex: gay men, barebacking, and harm reduction. Social Work and Society, v. 51, n. 2, p. 106-113, 2006.

SPINK, M. J. Trópicos do discurso sobre risco: risco-aventura como metáfora na modernidade tardia. Cadernos de Saúde Pública, Rio de Janeiro, v. 17, n. 6, p. 1277-1311, 2001.

PETTIGREW, T. F.; MEERTENS, R. W. Subtle and blatand prejudice in Western Europe. European Journal of Social Psychology, v. 25, n. 1, p. 57-75, 1995.

SEARS, D. O.; HENRY, P. J. The origins of symbolic racism. Journal of Personality and Social Psychology, Washington, v. 85, n. 2, p. 259-275, 2003.

TAPERT, S. F. et al. Adolescent substance use and sexual risk-taking behavior. Journal of Adolescent Health, v. 28, n. 3, p. 181-189, 2001.

TAQUETTE, S. et al. A relação entre as características sociais e comportamentais da adolescente e as doenças sexualmente transmissíveis. Revista Associação Médica Brasileira, São Paulo, v. 51, n. 3, p. 148-152, 2005.

TORRES, C. V.; RODRIGUES, H. Normas sociais: conceito, mensuração e implicações para o Brasil. In: TORRES, C. V.; NEIVA, E. R. (Orgs.). Psicologia Social: principais temas e vertentes. Porto Alegre: Artmed, 2011. p. 100-133.

VALA, J. Representações sociais e psicologia social do conhecimento cotidiano. In: VALA, J.; MONTEIRO, M. B. (Orgs.). Psicologia social. Lisboa: Fundação Calouste Gulbenkian, 2000. p. $457-502$.

WAGNER, W. Sócio-gênese e características das representações sociais. In: MOREIRA, A. S. P.; OLIVEIRA D. C. (Eds.). Estudos interdisciplinares de representação social. Goiânia: AB, 1998. p. 03-25. 
WOLITSKI, R. J. The emergence of barebacking among gay and bisexual men in the United States: a public health perspective. Journal of Gay \& Lesbian Psychotherapy, v. 9, n. 3/4, p. 9-34, 2005.

Submissão em: 20/05/2015

Revisão em: 16/11/2015

Aceite em: 16/11/2015

Andréia Isabel Giacomozzi é professora adjunta do Departamento de Psicologia da UFSC. Tem experiência na área de Psicologia, com ênfase em Pesquisa em Psicologia Social e da Saúde, atuando principalmente nos seguintes temas: Saúde

- Doença, Aids, Sexualidade, Adolescência, Uso/Abuso de drogas e Violências. É vinculada ao PPGP UFSC.

Endereço: UFSC. Programa de pós-graduação em Psicologia/CFH. Campus universitário. Trindade. Florianóolis/SC, Brasil. E-mail: agiacomozzi@hotmail.com

Nilceia Antunes é psicóloga da Secretaria Municipal de Saúde de Florianópolis. E-mail: nilceiaantunespsi@gmail.com

Kelly Vieira Meira é graduanda em Ciências Sociais/ UFSC.

E-mail: kellyvieirameira@gmail.com

Beatriz Pires Coltro é graduanda em Psicologia/ UFSC. E-mail: biacoltro@hotmail.com 